Rio Janeiro, noch mit der China nova surinamensis identisch, sondern von beiden durchaus verschieden sei. Das Pulver der rothen Parachina erschien auffallend faserig, blassbraunroth. Die Abkochung war heiss fast durchsichtig, dunkel braunroth, kalt sehr trübe und schmulzig rothbraun. Die chemische Untersuchung ergab in $16 \mathrm{Un}$ zen: $120 \mathrm{Gr}$. reine Chinovasäure und $2 \mathrm{Gr}$. Cinchonin, aber weit mehr oxydirten Gerbestoff, als die verwandten Rinden besitzen. (Buchn. Repert. Bd.46. Hft. 3.)

Overbeck.

\title{
Chemische Untersuchung der Mercurialis annua.
}

Diese Untersuchung ist von A. Buchner sen. angestellt worden. Das Bingelkraut war Ende Juni's, als die Pllanze in voller Kraft und Blüthe stand. gesammelt. Das lufturockne Kraut enthält noch 10 Proc. freies Wasser, der scharf ausgetrocknete giebt 46 Proc. auflösbare Bestandtheile und 54 Proc. Rückstand. Der Eiweissgehalt der Mercurialis annua ist sehr bedeutend. Buchner fand ferner als Hauptbestandtheile milden amorphen Bitterstoff, salpetersaures und schwefelsaures Kali, sauren äpfelsauren Kalk, Salmiak und salzsauren Kalk, ausserdem phosphorsauren Kalk, Pectin, Gummi, Zucker, Holzsubstanz, Chlorophyll, nebst ein wenig einer öligharzigen Substanz und etwas Indig. Aus der Summe seiner Versuche zieht Buchner den Schluss, dass die arzneilich wirksamen Bestandiheile des Bingelkraules Salze und Extractivstoffe sind, welche bei vorsichtigem Trocknen desselben keine wesentlichen Veränderungen erleiden. (Buchn. Repert. Bd. 46. H(t.2.) Overbeck.

\section{Arten der Alkornokorinde.}

J. Pere ir a weist nach, dass unter obigem Namen zwei verschiedene Rinden im Handel vorkommen, von denen die eine von einem europäischen Baume, die andere aus Amerika stammt. Er unterscheidet daher:

1) Europäische Alkornokorinde, von $Q$ uercu s suber, ist nicht die der französischen und deutschen Pharmakognosten. Diese wird von den Gerbern gebraucht und bauptsächlich aus Spanien und Italien bezogen.

2) Amerikanische Alkornokorinde, die der deutschen und französischen Pharmakognosten. Diess ist die ächte officinelle Alkornokorinde. Sie kam zuerst im Jahre 1804 durch-Don Joaquim Jove nach Europa, wurde aber erst 1814 in Deutschland bekannt. Die Mutterpflanze wird

Arch. d. Pharm. CIII. Bds. 3. Hft. 
von verschiedenen Autoren verschieden benannt, hald zu den Cupuliferen, bald zu den Euphorbiaceen, Apocyneen, Guttiferen, Leguminosen und Malpighiaceen gerechnet; und sonst Alchornea latifolia, später aber Byrsonima crassifolia und Malpighia crassifolia und Malpighia Maurella dafür angegeben. P er e ir a selbst wagt sich nicht bestimmt für die systematische Stellung der Mutterpflanze zu entscheiden, indem nach Hancock's Nachrichten von den eben genannten Pflanzen die Alkornokorinde nicht abstammen könne; charakterisirt die Rinde selbst aber folgendermassen: Die amerikanische Alkornokorinde kommt in grossen, flachen, etwas gewölbten Stücken vor, welche der stärkeren flachen Chinarinde ähnlich sind; sie sind $4-10$ Zoll lang. 2-4 Zoll breit und 4-8 Linien dick. Die Epidermis fehlt gewöhnlich. Aeusserlich ist die Rinde röthlich oder dunkelzimmtbraun, auf der inneren Fläche blasser. Sie schmeckt schwach bitter. Nach Geiger enthält sie rothbraunes geschmackloses Harz, besonderen Gerbestoff, bitteren Extractivstoff, unlöslichen Extractivstoff, gummigen Extractivstoff mit Kalksalzen, bittere, schleimige und gallertartige Materie und Pflanzenfaser. Biltz fand Alkornin, oxydirten Gerbestoff (?), Gerbestoff mit Kalksalzen, gummigen Extractivstoff mit Stärkmehl, eine stickstofthaltige Materie, ein saures Kalksalz und Faser. (Buchn. Repert. Bd. 46. Bft.1.)

Overbeck.

\section{Rothe Färbung der Blätter im Herbste.}

G. C. Wiltstein hat sich bemüht, die Fragen: ob das Roth der Blätter im Herbste aus dem Grün entstehe, oder ob es einem anderen physiologischen Processe sein Dasein verdanke, und, welcher Natur dieses Roth sei, zu beantworten. Zu seinen Untersuchungen wählte er die Blätter des wilden Weinstocks, Vitis hederacea Ehrb., welche sich wegen ihrer constanten und prachtvollen Rothfärbung im Herbste besonders dazu eignen, und die er ilırem Entwickelungsgange nach beobachtete, nämlich Blätler vom 14. April, 24. April, 11. Mai, 15. Mai, 19. Mai, 23. Juni (wo zuerst eine blasspurpurrothe Färbung an einzelnen Stellen in der Oberhaut eintrat), 1. Aug., 29. Sept. (wo sie zum Theil schon braunroth, zum Theil noch grü waren, und jetzt fade, $n i c h t$ mehr sauer, wie früher schmeckten), vom 7. Oct. wo sie bis auf wenige kleine grine Stellen vollständig roth waren und anfangs fade, hintennach aber bitterlich adstringirend schmeckten. Indess wareu die dem Sonnenlichte nicht ausgesetzt gewe- 